\section{Intravitreal triamcinolone acetonide for macular oedema owing to retinal vein occlusion}

PJ Patel, I Zaheer and N Karia
Department of Ophthalmology, Southend Hospital NHS Trust, Prittlewell Chase, Westcliff-On-Sea, Southend, Essex, UK

Correspondence: N Karia, Department of Ophthalmology, Southend Hospital NHS Trust, Prittlewell Chase, Westcliff-On-Sea, Southend, Essex SSO ORY, UK Tel: + 441702 221271; Fax: +44 1702221279 E-mail: niral.karia@ southend.nhs.uk

Received: 17 February 2006 Accepted: 6 June 2006 Published online: 11 August 2006

Proprietary interest: none

\begin{abstract}
Purpose To assess the long-term safety and efficacy of intravitreal triamcinolone acetonide injection in the management of macular oedema caused by central, hemi-, and branch retinal vein occlusion (CRVO, HRVO, or BRVO).

Methods This prospective, interventional case series included 13 patients (13 eyes) with retinal vein occlusion and macular oedema. They received an intravitreal injection of $4 \mathrm{mg}$ triamcinolone acetonide. Follow-up was for 1 year with repeat injections where appropriate. Outcome measures were visual acuity and macular thickness measured using ocular coherence tomography (OCT).

Results There were four patients with CRVO, one with HRVO, and eight with BRVO (13 eyes). Mean duration of symptoms before intravitreal triamcinolone acetonide injection was 6.8 months (SD 4.5 months). Eight eyes $(62 \%)$ responded well with improved visual acuity and macular thickness 1-3 months postinjection. All eight eyes developed recurrent macular oedema and five received repeat injections. Three patients declined a second injection. No improvement in visual acuity or OCT macular thickness was seen after the second injection with visual acuity returning to baseline levels at 1-year followup. Three eyes $(23 \%)$ showed no response to the initial injection (no improvement in macular thickness or visual acuity). Seven patients $(54 \%)$ had a rise in intraocular pressure with six $(46 \%)$ requiring treatment. Conclusions Intravitreal injection of triamcinolone acetonide is effective as a shortterm treatment of macular oedema owing to retinal vein occlusion, improving both visual acuity and macular thickness. However, this
\end{abstract}

effectiveness is not maintained after 1 year despite repeat injections.

Eye (2008) 22, 60-64; doi:10.1038/sj.eye.6702518; published online 11 August 2006

Keywords: triamcinolone acetonide; intraocular steroids; macular oedema; retinal vein occlusion

\section{Introduction}

Intravitreal triamcinolone acetonide has been used in the treatment of macular oedema due to a variety of retinal vascular disorders. ${ }^{1-3}$ It has gained in popularity as a treatment for macular oedema, as studies have shown improved visual acuity and reduced macular thickness following intravitreal triamcinolone acetonide injection. However, most studies suggesting a treatment benefit have been limited by the short follow-up of treated patients. Recent studies with longer follow-up have reported mixed results, with Williamson and $\mathrm{O}^{\prime}$ Donnell $^{4}$ not showing a sustained benefit of intravitreal triamcinolone for macular oedema owing to CRVO after 6 months of treatment despite repeat injections, but Cekic et $a l^{5}$ reporting improved outcomes in treating macular oedema owing to BRVO after 13 months of follow-up.

In addition, there have been reports of potentially serious ocular complications, including raised intraocular pressure (IOP) ${ }^{6}$ and endophthalmitis (sterile ${ }^{7}$ and infective ${ }^{8}$ ) following intravitreal triamcinolone acetonide injection.

Retinal vein occlusion comprises a group of diseases with heterogeneous pathophysiology, but with a final common pathway of vascular occlusion leading to increased retinal vascular 
permeability, retinal hypoxia, and macular oedema. Retinal vein occlusion results from obstruction of a retinal vein either at (CRVO) or just before the lamina cribosa (HRVO) or at an arteriovenous crossing (BRVO). The prognosis in CRVO and HRVO is generally poor with irreversible severe visual loss from chronic macular oedema and retinal ischaemia in the majority of patients. ${ }^{9}$ Treatment for CRVO has included bypassing the occluded vein with a chorioretinal venous anastomosis (created surgically ${ }^{10}$ or by laser ${ }^{11}$ ) and more recently surgical treatment with radial optic neurotomy ${ }^{12}$ has been attempted. Despite these approaches, there is no well-established, effective treatment for macular oedema owing to CRVO and it remains a condition with a poor prognosis. ${ }^{9}$ Patients with macular oedema owing to BRVO have a more variable prognosis, but a significant proportion also suffer severe visual loss. ${ }^{13-15}$

There have been many reports of the effectiveness of intravitreal triamcinolone acetonide injection in treating macular oedema due to retinal vein occlusion, $1,16,17$ but the long-term benefit of treatment has yet to be established. The aim of this study was to investigate the long-term safety and efficacy of intravitreal triamcinolone acetonide in the treatment of macular oedema due to retinal vein occlusion.

\section{Materials and methods}

Thirteen eyes of 13 patients with macular oedema due to retinal vein occlusion were recruited into the study. All patients had a visual acuity of $6 / 18$ or worse at enrolment and informed consent was sought from the patients with all the potential risks of intravitreal triamcinolone acetonide injection explained fully. All the patients received intravitreal triamcinolone acetonide injection as a primary treatment for macular oedema. The BRVO patients with macular oedema included in the study were those with poor vision who chose to have intravitreal triamcinolone acetonide injection rather than macular grid treatment as per the BRVOS. ${ }^{14}$ Baseline routine ophthalmological examination of all study patients was carried out at the start of the study and was repeated at subsequent visits. The examination included best-corrected Snellen visual acuity measurement (converted to logarithm of the minimum angle of resolution ( $\log$ MAR)), slit-lamp biomicroscopy, Goldmann applanation tonometry, fundus examination, and optical coherence tomography (OCT 2, Zeiss instruments) analysis of $1 \mathrm{~mm}$ central macular thickness.

Intravitreal triamcinolone injection was performed in an outpatient minor operations room, with topical amethocaine $1 \%$ applied to the ocular surface before preparation with $5 \%$ povidone iodine. An eyelid speculum was inserted before the injection and further topical amethocaine was applied directly to the conjunctiva at the injection site $4 \mathrm{~mm}$ posterior to the limbus. The injection consisted of $4 \mathrm{mg}(0.1 \mathrm{ml})$ triamcinolone acetonide administered via a tuberculin syringe with a $27 \mathrm{G}$ needle. The drug was drawn up as an aqueous suspension using a sterile technique, with no attempt made to filter or separate the drug from the preservative containing vehicle. After injection, topical chloramphenicol $0.5 \%$ was applied and a slit-lamp examination was carried out to ensure the presence of the drug in the vitreous cavity and to measure the IOP. An anterior chamber paracentesis was performed to lower the IOP in patients with an IOP sufficient to cause nonperfusion or pulsation of the central retinal artery. Patients were given topical chloramphenicol drops four times daily, until they were reviewed after 1 week. They were then reviewed every 1-2 months after the initial injection. Intravitreal triamcinolone was seen in situ for a minimum of 10 weeks in all patients. Repeat injections were performed if there was recurrence in macular oedema after a successful initial injection (reduction in central macular thickness on OCT with improvement in visual acuity with no complications of injection such as raised IOP requiring treatment). Patients were followed up for 1 year after the initial injection.

Statistical analysis was performed using a statistical software package (SPSS version 11.5). The two-tailed Student's $t$-test and the Mann-Whitney test were used where appropriate with $P<0.05$ taken as statistically significant.

\section{Results}

A total of 13 eyes of 13 patients were recruited for the study. Table 1 summarises the baseline characteristics of the patients in the study. There were four patients with CRVO, one patient with HRVO, and eight patients with BRVO. OCT macular thickness measurement was not possible for some patients with poor macular fixation as this affected data acquisition. The duration of macular oedema (on the basis of symptoms of reduced vision) before intravitreal triamcinolone injection was 6.5 months (range 1-16 months). Table 2 summarises the visual acuity results. At its best, visual acuity improved by two or more Snellen lines in eight $(62 \%)$ eyes, but this improvement was not maintained despite further injections of triamcinolone where appropriate, and by the end of follow-up, 12 of 13 (92\%) eyes were within one Snellen line of the presenting visual acuity. One eye with BRVO failed to respond to injection of intravitreal triamcinolone and lost vision from $6 / 18$ to $6 / 60$ over 14 months owing to persistent macular oedema and eventual pigmentary macular change despite argon grid 
Table 1 Patient summary

\begin{tabular}{lccclc}
\hline Patient & Sex & $\begin{array}{c}\text { Age } \\
\text { (years) }\end{array}$ & Eye & Diagnosis & $\begin{array}{c}\text { Duration of } \\
\text { symptoms/ } \\
\text { RVO (months) }\end{array}$ \\
\hline 1 & F & 84 & L & CRVO & 16 \\
2 & F & 80 & R & CRVO & 12 \\
3 & M & 71 & R & CRVO & 2 \\
4 & F & 78 & L & CRVO & 12 \\
5 & M & 60 & R & HRVO & 1 \\
6 & F & 68 & L & BRVO & 2.5 \\
7 & F & 61 & R & BRVO & 10 \\
8 & F & 68 & L & BRVO & 8 \\
9 & M & 81 & L & BRVO & 4 \\
10 & M & 69 & R & BRVO & 4 \\
11 & F & 78 & R & BRVO & 1.25 \\
12 & M & 53 & R & BRVO & 8 \\
13 & M & 75 & R & BRVO & 4 \\
\hline
\end{tabular}

$\mathrm{F}=$ female; $\mathrm{M}=$ male; $\mathrm{L}=$ left; $\mathrm{R}=$ right; $\mathrm{CRVO}=$ central retinal vein occlusion; $\mathrm{HRVO}=$ hemiretinal vein occlusion; $\mathrm{BRVO}=$ branch retinal vein occlusion; $\mathrm{RVO}=$ retinal vein occlusion.

laser treatment. The mean visual acuity at presentation was $6 / 45$ (logMAR 0.88 , SD 0.44), and after treatment, at best, the mean visual acuity improved significantly to $6 / 15$ (logMAR 0.42, SD 0.30, $P=0.002$ ), but by the end of follow-up, the mean visual acuity was only $6 / 75$ ( $\log$ MAR $1.10, \mathrm{SD} 0.58, P=0.48$, not significant). Eight patients received a single injection and the remaining five patients received two injections by the end of follow-up (mean 14.6 months, SD 4.1 months).

One millimetre mean central macular thickness decreased significantly by $259 \mu \mathrm{m}$ at best after treatment (a $45 \%$ decrease) from $530 \mu \mathrm{m}$ (SD $85 \mu \mathrm{m}$ ) to $271 \mu \mathrm{m}$ (SD $94 \mu \mathrm{m} ; P=0.000017$ ), with five eyes achieving a thickness less than $250 \mu \mathrm{m}$ (Table 3 and Figure 1). However, this improvement was not maintained despite repeat injections in eyes with recurrent macular oedema and at the end of follow-up, a final mean macular thickness of $523 \mu \mathrm{m}$ (SD $178 \mu \mathrm{m}, P=0.92$, not significant) was seen.

An IOP rise was seen in eight of $13(62 \%)$ eyes during follow-up. Four eyes achieved a maximum IOP of less than $30 \mathrm{mmHg}$. The highest IOP recorded was $40 \mathrm{mmHg}$ and this was seen with two eyes both treated adequately with topical medication. In total, five eyes (38\%) required IOP lowering medication at the end of follow-up. None of the patients required trabeculectomy. There were no cases of endophthalmitis, vitreous haemorrhage, retinal detachment, visually significant cataract, or acute visual loss.

\section{Discussion}

Retinal vein occlusion comprises a heterogeneous group of disorders with as yet poorly understood pathophysiology, but with a final common pathway
Table 2 Visual acuity results

\begin{tabular}{ccccc}
\hline Patient & \multicolumn{3}{c}{ Snellen visual acuity (logMAR) } & $\begin{array}{c}\text { Follow-up } \\
\text { (months) }\end{array}$ \\
\cline { 2 - 4 } & Initial & Best postinjection & Final & \\
\hline 1 & $6 / 36(0.78)$ & $6 / 36(0.78)$ & $6 / 36(0.78)$ & 14 \\
2 & $6 / 36(0.78)$ & $6 / 36(0.78)$ & $6 / 60(1)$ & 16 \\
3 & CF (1.6) & $6 / 9(0.18)$ & $6 / 60(1)$ & 26 \\
4 & $6 / 18(0.48)$ & $6 / 9(0.18)$ & $6 / 12(0.3)$ & 12 \\
5 & $6 / 18(0.48)$ & $6 / 6(0)$ & $6 / 12(0.3)$ & 12 \\
6 & $6 / 36(0.78)$ & $6 / 9(0.18)$ & $6 / 60(1)$ & 18 \\
7 & CF (1.6) & $6 / 18(0.48)$ & CF (1.6) & 12 \\
8 & $6 / 36(0.78)$ & $6 / 24(0.6)$ & $6 / 24(0.6)$ & 12 \\
9 & $6 / 24(0.6)$ & $6 / 12(0.3)$ & $6 / 24(0.6)$ & 12 \\
10 & $6 / 60(1)$ & $6 / 12(0.3)$ & $6 / 60(1)$ & 12 \\
11 & CF (1.6) & $6 / 60(1)$ & $6 / 60(1)$ & 12 \\
12 & $6 / 18(0.48)$ & $6 / 9(0.18)$ & $6 / 18(0.48)$ & 17 \\
13 & $6 / 18(0.48)$ & $6 / 18(0.48)$ & CF (1.6) & 14 \\
\hline
\end{tabular}

Table 3 Optical coherence tomography measurements of $1 \mathrm{~mm}$ central macular thickness

\begin{tabular}{rccc}
\hline Patient & \multicolumn{3}{c}{$1 \mathrm{~mm}$ central macular thickness $(\mu \mathrm{m})$} \\
\cline { 2 - 4 } & Initial & Best postinjection & Final \\
\hline 1 & Not measurable & Not measurable & Not measurable \\
2 & Not measurable & Not measurable & Not measurable \\
3 & 580 & 158 & Not measurable \\
4 & 410 & 178 & 408 \\
5 & 581 & 221 & 400 \\
6 & 417 & 291 & Not measurable \\
7 & Not measurable & 279 & Not measurable \\
8 & 580 & 226 & Not measurable \\
9 & Not measurable & Not measurable & 404 \\
10 & 608 & 248 & 854 \\
11 & 599 & 349 & Not measurable \\
12 & Not measurable & 269 & 484 \\
13 & 462 & 488 & 586 \\
\hline
\end{tabular}
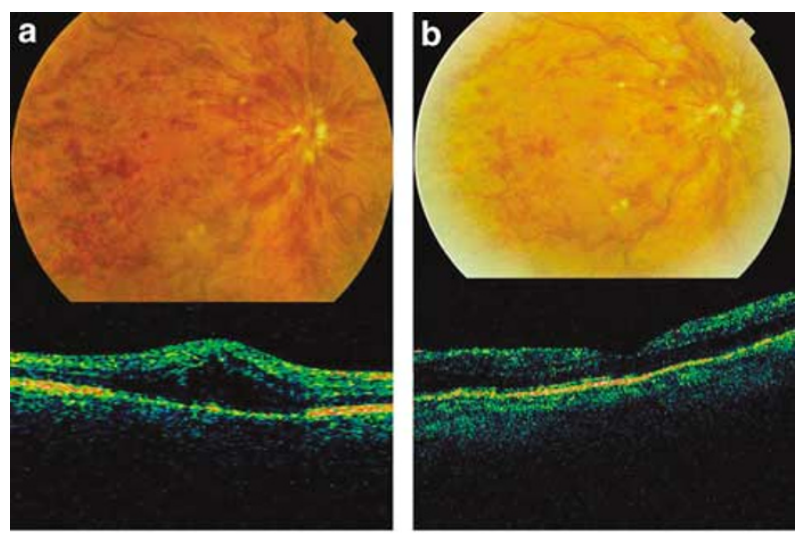

Figure 1 Fundus photos and optical coherence images of patient 3 with CRVO and macular oedema (a) at presentation and (b) 1 month postintravitreal triamcinolone injection. 
of retinal ischaemia, breakdown of inner blood-retinal barrier, and macular oedema.

Treatment of macular oedema secondary to retinal vein occlusion remains frustrating often with poor visual outcomes. Studies have shown promising results from intravitreal triamcinolone acetonide injection; however, most studies have had limited patient follow-up and the long-term efficacy of the treatment is yet to be conclusively proven.

This study suggests that though effective in improving visual acuity and reducing macular oedema in patients with retinal vein occlusion, intravitreal triamcinolone injections only provide temporary benefit with no visual improvement after 12 months of follow-up.

Intravitreal corticosteroid injection is thought to act through a variety of mechanisms in reducing macular oedema associated with retinal vein occlusion including reducing vascular endothelial growth factor (VEGF) production, ${ }^{18}$ thus helping to stabilise the inner bloodretinal barrier. Other triamcinolone-mediated effects may include the inhibition of other proinflammatory mediators such as prostaglandins and leukotrienes (involved in the pathogenesis of pseudophakic macular oedema ${ }^{19}$ ) and the inhibition of protein kinase $C$ (implicated in VEGF-induced retinal permeability seen in diabetic macular oedema ${ }^{20}$ ). However, these effects do not directly address the underlying pathophysiological abnormalities that cause venous occlusion and this study suggests that despite an initial response to intravitreal triamcinolone injection, macular oedema will recur and appears to become increasingly resistant to the effects of intravitreal corticosteroid through a poorly understood mechanism.

In this study, the mean duration of macular oedema (based on symptoms) before intravitreal triamcinolone injection was 6.5 months. It may be that long-standing macular oedema is associated with more disruption of macular cellular architecture and function leading to poor long-term outcomes of repeat intravitreal triamcinolone injection. However, in two patients (one with CRVO, one with HRVO) with macular oedema of less than 2 months duration, the final visual outcome was similar to that of the other patients in the study with macular oedema of longer duration (although these two patients initially had an impressive response to intravitreal triamcinolone with improved visual acuity from counting fingers vision to $6 / 9$ in the CRVO patient and $6 / 18$ to $6 / 6$ in the HRVO patient). It is also possible that these two patients had macular oedema of longer duration, but had only noticed symptoms of blurred vision for less than 2 months. The disappointing long-term visual acuity outcomes may also be owing to worsening macular ischaemia; however, as fundus fluorescein angiography was not routinely carried out, this possibility is difficult to rule out and is a potential weakness of the study.

In assessing the safety of intravitreal triamcinolone injection, this study agrees broadly with other published studies, ${ }^{21,22}$ with raised IOP being the most common complication of treatment and $62 \%$ of patients in this study suffered a rise in IOP with five (38\%) still requiring treatment at the end of follow-up. There were no cases of visually significant cataract, vitreous haemorrhage, retinal detachment, or endophthalmitis (sterile or infective).

The findings from this study support those of Williamson and O'Donnell, ${ }^{4}$ who found only short-term benefit of intravitreal triamcinolone in treating macular oedema owing to nonischaemic CRVO in a recent noncomparative, interventional case series.

The role of intravitreal triamcinolone in the treatment paradigm of retinal vein occlusion may be as an adjunct in the treatment of selected cases. In cases of recent onset CRVO, combining intravitreal triamcinolone to reduce macular oedema in the short term with a treatment modality that restores retinal blood flow (eg, chorioretinal venous anastomosis or radial optic neurotomy) may yield better results. In cases of BRVO with gross and persistent macular thickening, intravitreal triamcinolone may be used to reduce macular thickness before macular grid laser, therefore allowing more effective laser treatment. Further study is needed in this area, ${ }^{23}$ and the results of the standard care $v s$ corticosteroid for retinal vein occlusion (SCORE) study are avidly awaited.

This prospective, interventional case series suggests that intravitreal triamcinolone injection provides only short-term benefit for patients with macular oedema due to retinal vein occlusion, with no sustained improvement in visual acuity after 1-year follow-up (despite repeated injections where appropriate).

\section{References}

1 Greenberg PB, Martidis A, Rogers AH, Duker JS, Reichel E. Intravitreal triamcinolone acetonide for macular oedema due to central retinal vein occlusion. Br J Ophthalmol 2002; 86: $247-248$.

2 Martidis A, Duker JS, Greenberg PB, Rogers AH, Puliafito $\mathrm{CA}$, Reichel $\mathrm{E}$ et al. Intravitreal triamcinolone acetonide for refractory diabetic macular oedema. Ophthalmology 2002; 109: 920-927.

3 Antcliff RJ, Spalton DJ, Stanford MR, Graham EM, Ffytche TJ, Marshall J. Intravitreal triamcinolone for uveitic cystoid macular oedema: an optical coherence tomography study. Ophthalmology 2001; 108: 765-772.

4 Williamson TH, O'Donnell A. Intravitreal triamcinolone acetonide for cystoid macular edema in nonischemic central retinal vein occlusion. Am J Ophthalmol 2005; 139: 860-866. 
5 Cekic O, Chang S, Tseng JJ, Barile GR, Del Priore LV, Weissman $\mathrm{H}$ et al. Intravitreal triamcinolone injection for treatment of macular edema secondary to branch retinal vein occlusion. Retina 2005; 25: 851-855.

6 Kaushik S, Gupta V, Gupta A, Dogra MR, Singh R. Intractable glaucoma following intravitreal triamcinolone in central retinal vein occlusion. Am J Ophthalmol 2004; 137: 758-760.

7 Moshfeghi DM, Kaiser PK, Scott IU, Sears JE, Benz M, Sinesterra JP et al. Acute endophthalmitis following intravitreal triamcinolone acetonide injection. $\mathrm{Am} \mathrm{J}$ Ophthalmol 2003; 136: 791-796.

8 Roth DB, Chieh J, Spirn MJ, Green SN, Yarian DL, Chaudhry NA. Noninfectious endophthalmitis associated with intravitreal triamcinolone injection. Arch Ophthalmol 2003; 121: $1279-1282$.

9 The Central Retinal Vein Occlusion Study Group. Natural history and clinical management of central retinal vein occlusion. Arch Ophthalmol 1997; 115: 486-491.

10 Fekrat S, de Juan Jr E. Chorioretinal venous anastomosis for central retinal vein occlusion: transvitreal venipuncture. Ophthal Surg Lasers 1999; 30: 52-55.

11 Fekrat S, Goldberg MF, Finkelstein D. Laser-induced chorioretinal venous anastomosis for nonischaemic central or branch retinal vein occlusion [comment]. Arch Ophthalmol 1998; 116: 43-52.

12 Opremcak EM, Bruce RA, Lomeo MD, Ridenour CD, Letson $\mathrm{AD}$, Rehmar AJ. Radial optic neurotomy for central retinal vein occlusion: a retrospective pilot study of 11 consecutive cases. Retina 2001; 21: 408-415.

13 Branch Retinal Vein Occlusion Study Group. Argon laser scatter photocoagulation for prevention of neovascularisation and vitreous haemorrhage in branch vein occlusion. A randomised clinical trial. Arch Ophthalmol 1984; 104: 34-41.

14 Branch Retinal Vein Occlusion Study Group. Argon laser scatter photocoagulation for macular edema in branch vein occlusion. Am J Ophthalmol 1984; 98: 271-282.
15 Michels RG, Gass JDM. The natural course of retinal branch vein occlusion. Trans Am Acad Ophthalmol Otolaryngol 1974; 78: OP166-OP177.

16 Park $\mathrm{CH}$, Jaffe GJ, Fekrat S. Intravitreal triamcinolone acetonide in eyes with cystoid macular edema associated with central retinal vein occlusion. Am J Ophthalmol 2003; 136: $419-425$.

17 Ip MS, Gottlieb JL, Kahana A, Scott IU, Altaweel MM, Blodi BA et al. Intravitreal triamcinolone for the treatment of macular edema associated with central retinal vein occlusion. Arch Ophthalmol 2004; 122: 1131-1136.

18 Nauck M, Karakiulakis G, Perruchoud AP, Papakonstantinou E, Roth M. Corticosteriods inhibit the expression of the vascular endothelial growth factor gene in human vascular smooth muscle cells. Eur J Pharmacol 1998; 341: 309-315.

19 Funatsu H, Yamashita H, Noma H, Mimura T, Yamashita T, Hori S. Increased levels of vascular endothelial growth factor and interleukin-6 in the aqueous humor of diabetics with macular edema. Am J Ophthalmol 2002; 133: 70-77.

20 Aiello LP, Bursell SE, Clermont A, Duh E, Ishii H, Takagi $C$ et al. Vascular endothelial growth factor-induced retinal permeability is mediated by protein kinase $C$ in vivo and suppressed by an orally effective beta-isoform-selective inhibitor. Diabetes 1997; 46: 1473-1480.

21 Jonas JB, Kreissig I, Degenring R. Intraocular pressure after intravitreal injection of triamcinolone acetonide. $\mathrm{Br} J$ Ophthalmol 2003; 87: 24-27.

22 Wingate RJ, Beaumont PE. Intravitreal triamcinolone and elevated intraocular pressure. Aust N Z J Ophthalmol 1999; 27: 431-432.

23 Scott IU, Ip MS. It's time for a clinical trial to investigate intravitreal triamcinolone for macular edema due to retinal vein occlusion: the SCORE study. Arch Ophthalmol 2005; 123: 581-582. 